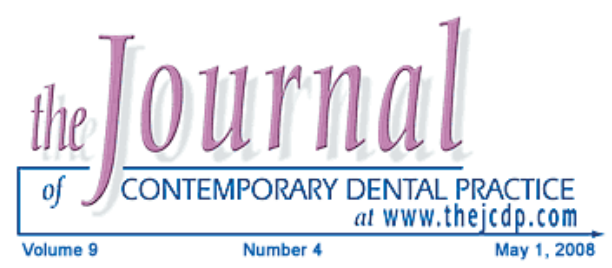

\title{
Clinical Diagnosis and Oral Rehabilitation of a Patient with Amelogenesis imperfecta: A Case Report
}
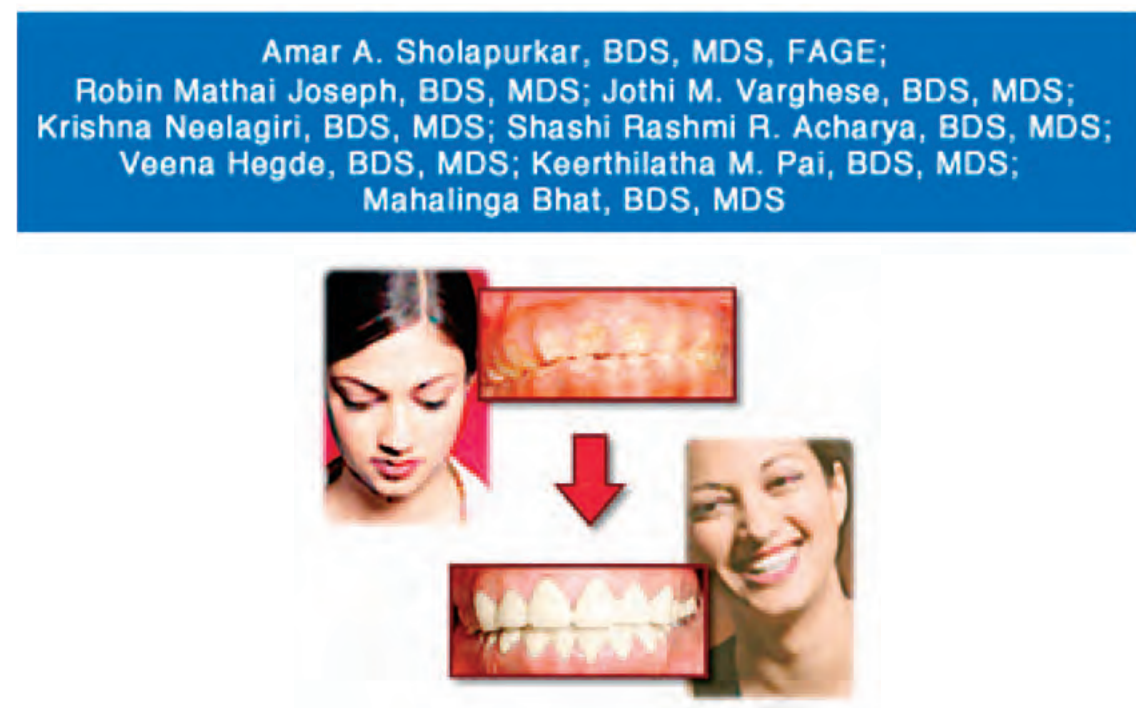

\section{Abstract}

Aim: This clinical report describes the oral rehabilitation of a young female patient diagnosed with the hypocalcified, autosomal recessive type of Amelogenesis imperfecta (AI). A brief discussion on diagnosis of Al is also included.

Background: Al has been defined as a group of hereditary enamel defects not associated with evidence of systemic disease. It can be characterized by enamel hypoplasia and/or hypomaturation or hypocalcification of the existing teeth. Restoration for patients with this condition should be oriented toward the functional and esthetic rehabilitation and the protection of these teeth.

Report: A 31-year-old female patient presented with concerns including extreme sensitivity; dissatisfaction with size, shape, and shade of teeth; and poor masticatory efficiency. She was very conscious about the appearance of her teeth and reported that her primary dentition was affected in the same manner. The specific objectives of this treatment were to eliminate tooth sensitivity, enhance esthetics, and restore masticatory function. Treatment included crown lengthening procedures and placement of anterior and posterior metalceramic crowns. A 12-month follow-up with clinical and radiographic examinations revealed no evidence of any untoward effects of the treatment on the restored teeth or their supporting structures.

Summary: Management of a patient with $\mathrm{Al}$ is a challenge for the clinician. The treatment options vary considerably depending on several factors such as the age of the patient, socio-economic status, periodontal

(c) Seer Publishing 
condition, loss of tooth structure, severity of the disorder, and, most importantly, the patient's cooperation. The clinician has to consider the long-term prognosis of the treatment outcome. This clinical report describes the fabrication of metal ceramic and all metal crowns for the restoration of severely worn teeth in a patient with $\mathrm{Al}$ which requires meticulous maintenance of oral hygiene and patient co-operation.

Keywords: Amelogenesis imperfecta, Al, hereditary enamel defects, clinical diagnosis, full-mouth rehabilitation

Citation: Sholapurkar AA, Joseph RM, Varghese JM, Neelagiri K, Acharya SRR, Hegde V, Pai KM, Bhat M. Clinical Diagnosis and Oral Rehabilitation of a Patient with Amelogenesis imperfecta: A Case Report. J Contemp Dent Pract 2008 May; (9)4:092-098.

\section{Introduction}

Amelogenesis imperfecta (Al) has been defined as a complex group of hereditary enamel defects not associated with evidence of systemic disease ${ }^{1,2}$ affecting both primary and permanent dentitions. ${ }^{1}$ It is a rare enamel mineralization defect described by Spokes ${ }^{3}$ in 1890 as "hereditary brown teeth" with a reported incidence of $1: 14,000 .{ }^{4}$

Phenotypically $\mathrm{Al}$ is categorized into four broad groups: hypoplastic, hypomaturation, hypocalcified, and a hypomaturation-hypoplastic variety. Fifteen subtypes of $\mathrm{Al}$ exist phenotypically and based on modes of inheritance. This classification has been proposed by Witkop ${ }^{5}$ (Table 1).

The types are characterized as follows:

- Type-I: Lesions may appear as pin-point to pinhead sized pits scattered across the surfaces of teeth. The distribution of lesions may be generalized or localized, and the alteration of the enamel is a result of inadequate deposition of enamel matrix.

- Type-II: Also known as the hypomaturation type is associated with abnormalities in the maturation stages of enamel formation resulting in the enamel being opaque and chalky in appearance. The enamel layer is normal in thickness but softer than normal and can be easily detached from the underlying dentin.

- Type-III: The teeth have enamel that is insufficiently mineralized and clinically appears as severely worn teeth. It results from detachment of the enamel from dentin within a short period after tooth eruption. Teeth are very sensitive to thermal changes and appear dark brown in color.

- Type-IV: Al exhibits enamel hypoplasia in combination with hypomaturation. This variety is associated with taurodontism. The most common form of $\mathrm{Al}$ is the autosomal dominant hypocalcified type, followed by hypomaturation, and the hypoplastic type. ${ }^{6}$

Other associated findings in patients with $\mathrm{Al}$ include delayed eruption of teeth, taurodontism, congenitally missing teeth, crown and root resorption, and pulp calcification. ${ }^{7}$ Radiographically the density of enamel layer is lower than normal enamel. Hypoplastic enamel shows great variation in density and it may be difficult to distinguish it radiographically from underlying dentin.

$\mathrm{Al}$ is caused by mutations in a variety of genes that are critical for normal enamel formation. A total of about five genes [AMELX, ENAM, KLK4, MMP20, and DLX3 $]^{8,9}$ are known to be involved in enamel formation. Mutations of the amelogenin gene (AMELX) cause X-linked Al, while mutations of the enamelin (ENAM) gene causes autosomal inherited forms of Al. Other genes like Kallikrein 4 (KLK4), MMP-20, and DLX3 genes contribute to the etiologies of some other varieties of $\mathrm{Al}$ which is still under investigation.

Various treatment methods or strategies were initially instituted for Al patients such as the extraction of the compromised teeth and placement of a removable prosthesis or implant supported fixed or removable prosthesis. ${ }^{10}$ However, these procedures are very invasive and have greater incidence of complications. Numerous treatment modalities have been described for rehabilitation of patients with $\mathrm{Al} .^{10-17}$ Rehabilitation of patients with Al requires meticulous oral hygiene maintenance and patient cooperation.

This rare dental abnormality poses a major restorative challenge for the dentist. Using 
Table 1. Classification of $\mathrm{Al}$ according to Witkop ${ }^{5}$ (1989).

\begin{tabular}{|c|c|}
\hline Type I & Hypoplastic \\
\hline IA & Hypoplastic, pitted autosomal dominant \\
\hline IB & Hypoplastic, local autosomal dominant \\
\hline IC & Hypoplastic, local autosomal recessive \\
\hline ID & Hypoplastic, smooth autosomal dominant \\
\hline IE & Hypoplastic, smooth X-linked dominant \\
\hline IF & Hypoplastic, rough autosomal dominant \\
\hline IG & Enamel agenesis, autosomal recessive \\
\hline Type ॥ & Hypomaturation \\
\hline IIA & Hypomaturation, pigmented autosomal recessive \\
\hline IIB & Hypomaturation, $\mathrm{X}$-linked recessive \\
\hline IIC & Snow-capped teeth, autosomal dominant? \\
\hline Type III & Hypocalcified \\
\hline IIIA & Autosomal dominant \\
\hline IIIB & Autosomal recessive \\
\hline Type IV & Hypomaturation-hypoplastic with Taurodontism \\
\hline IVA & Hypomaturation-hypoplastic with taurodontism, autosomal dominant \\
\hline IVB & Hypoplastic-hypomaturation with taurodontism, autosomal dominant \\
\hline
\end{tabular}

conservative techniques desirable esthetics can be achieved, the teeth and supporting structures preserved, and a harmonious relationship created between the occlusion and temporomandibular articulation.

\section{Case Report}

\section{Diagnosis}

A 31-year-old female patient presented with considerable dental sensitivity and wear of her teeth. Her primary concerns included extreme sensitivity; dissatisfaction with size, shape, and shade of teeth; and poor masticatory efficiency. She was very conscious about the appearance of her teeth and reported that her primary dentition was affected in same manner. A detailed medical history, dental history, and social history was obtained but was noncontributory. The patient was questioned further about the presence of similar abnormalities in her family. She stated her grandfather had a similar defect in his teeth.

An extraoral examination revealed no abnormalities. Intraoral examination revealed a full complement of the permanent dentition. 
The incisal aspects of maxillary and mandibular anteriors were completely worn away exposing the pulp chambers (Figure 1).

The occlusal aspects of all the posterior teeth were also severely worn, however, the cervical and proximal enamel was found to be normal. The crowns were short and thin with the tooth surfaces being rough and dull. Deep carious lesions were seen in the right and left mandibular molars. The attrition of the molars resulted in a decrease of the vertical dimension of occlusion. The interocclusal distance at physiologic rest position was $7.3 \mathrm{~mm}$, and the centric occlusion position was coincident with the maximum intercuspal position. The gingival status was found to be good and well maintained. The oral hygiene of the patient was satisfactory.

A panoramic radiographic examination of the teeth revealed generalized defective enamel on all the teeth (Figure 2). The enamel of the teeth appeared to have the same radiodensity as dentin and the morphology of the roots were normal. The pulp chambers were normal with no evidence of calcification. The cementum, lamina dura, and bony trabeculations were within normal limits.

The hypocalcified variety of $\mathrm{Al}$ is characterized by enamel that is insufficiently mineralized. It is soft and easily lost over a short period if time following eruption. The current patient presented with similar clinical features such as the enamel being chipped off and the teeth severely worn exposing the pulps of several teeth. Hence, hypocalcified variety of Al was considered. A positive history of a similar problem with the patient's grandfather prompted an investigation into possible occurrences in other members of the family. Observations indicate the disease had skipped a generation in between the grandfather and the patient. The patient's siblings did not express the disease, suggesting a recessive inheritance (Figure 3). Based on the patient history and clinical examination a diagnosis of Al (hypocalcified autosomal recessive type) was made.

\section{Treatment}

To satisfy the patient's primary concerns, a treatment plan was developed to include an oral prophylaxis and oral hygiene instructions followed by lengthening of the clinical crowns

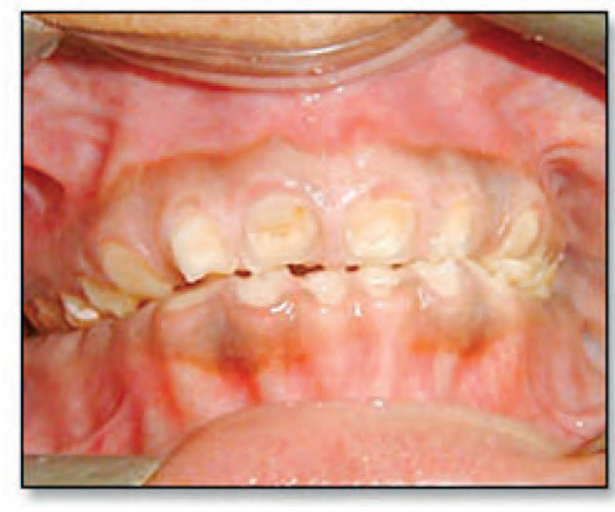

Figure 1. Pretreatment photograph of the patient with Al showing complete attrition of teeth.

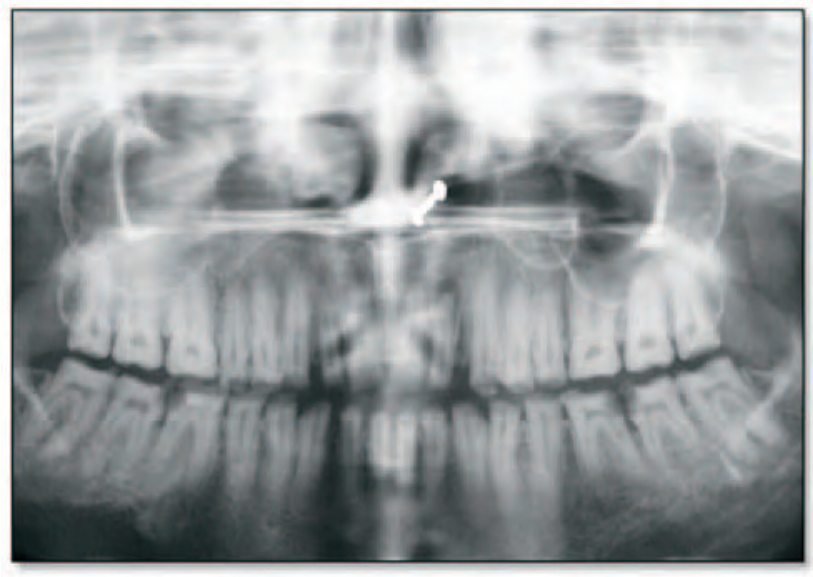

Figure 2. Panoramic radiograph showing generalized defective enamel in all teeth with its radiodensity being the same as the dentin. The morphology of roots is normal. A pseudocyst is apparent in the right maxillary sinus.
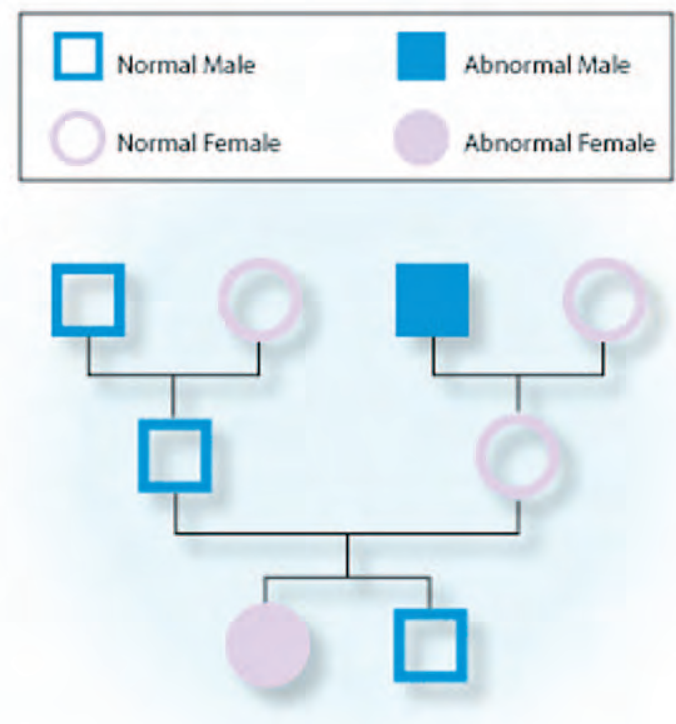

Figure 3. Pedigree chart of Al (hypocalcified autosomal recessive variety). 
of all teeth followed by placement of metalceramic crowns. The patient was prescribed $0.12 \%$ chlorohexidine gluconate mouth rinse twice daily. Since the heights of the crowns of the maxillary and mandibular teeth were inadequate for the fabrication of the prosthesis, an apically positioned flap was planned as a part of the crown lengthening procedure with consideration for biologic width dimensions. The surgical site was allowed to heal for three months. Finally, increase of crown height by approximately $2 \mathrm{~mm}$ was achieved. Figures 4 and 5 show the pretreatment and post-treatment photographs of the lower right quadrant.

Caries excavation was done for all carious teeth. Endodontic therapy was carried out on all teeth except the maxillary posterior teeth to address the multiple pulp exposures caused by the severe attrition.

Maxillary and mandibular complete-arch impressions were made using Hydrogum Soft irreversible hydrocolloid (Thixotropic, Zhermach, Italy) impression material. Diagnostic casts were fabricated from Type-III dental stone (Pankaj Industries, Mumbai, India) and mounted on a Whipmix semiadjustable articulator using a face bow transfer. Bite registration using Type II modeling wax (Hyderabad Dental Products, Hyderabad, India) was made at an increased vertical dimension of $5 \mathrm{~mm}$ with $3 \mathrm{~mm}$ of freeway space. Using these records a splint was fabricated with heat-cured polymethyl methacrylate acrylic resin (DPI-Heat cure, Dental products of India Ltd, Mumbai, India). This splint was used to remove muscle engram (muscle deprogramming). The patient used the splint for three months while the teeth were restored with temporary restorations without any complications.

After completion of endodontic therapy, the maxillary anterior teeth were prepared with post spaces for cast post cores and for prefabricated posts for the mandibular anterior teeth. Composite core build-ups (Clearfil Photocore, Kuraray Dental, Japan) were fabricated for the premolars and the right first molar in order to increase the crown height. (Figure 6)

In order to avoid trauma to the gingival sulcus a thin retraction cord was inserted into the

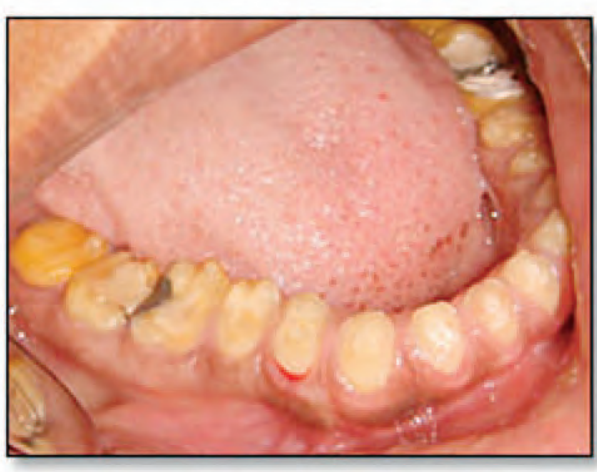

Figure 4. Lateral view of the mandibular teeth showing inadequate crown height for the fabrication of a prosthesis.

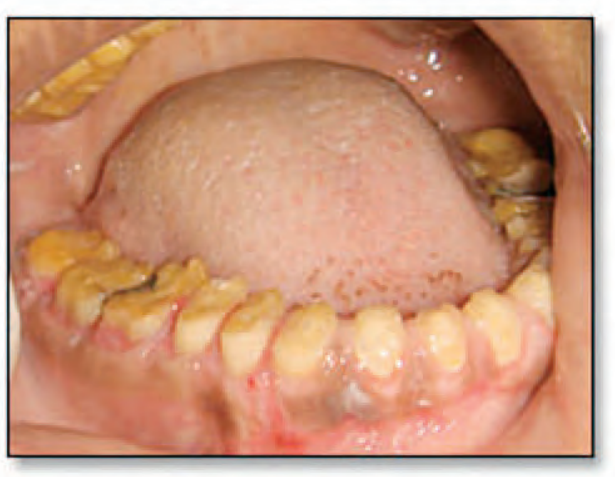

Figure 5. Post treatment photograph of the patient showing surgically lengthened crowns with an increase in the crown height by approximately $2 \mathrm{~mm}$.

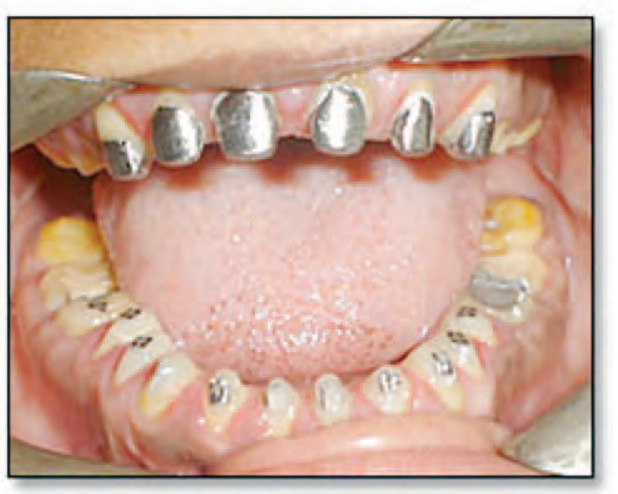

Figure 6. Anterior view of the teeth showing cast post and core in maxillary anteriors and prefabricated posts and composite build up in mandibular anteriors. 
sulcus prior to preparation. Crown preparations were done for porcelain-fused-to-metal (PFM) restorations for the maxillary and mandibular anteriors, premolars, and maxillary first molars; on the remaining teeth all-metal restorations were used. Gingival displacement prior to impression making was done using a non-hemostatic gingival magic foam cord retraction system (Ultradent, South Jordan, UT, USA).

Impressions were made with addition polyvinyl siloxane material (Reprosil, Dentsply/Caulk; Milford, DE, USA) using the putty wash technique (Panasil Putty Soft, Dentsply Kettenbach, Germany). Full-mouth, heat-cured provisional restorations (Figure 7) were fabricated at the desired vertical dimension (with $3 \mathrm{~mm}$ freeway space) using methyl methacrylate acrylic resin. The provisional restorations were temporarily cemented using Provicol, eugenol free $\mathrm{Ca}(\mathrm{OH})_{2}$ cement (Voco, Cuxhaven, Germany).

The patient wore the provisional restorations at the newly established occlusal vertical dimension for three months. Final impressions were made using the putty-wash technique and casts were prepared using Type IV stone in conjunction with the Pindex system (Confident, Bangalore, India) to create removable dies. The working casts were mounted onto the Hanau Widevue semiadjustable articulator (Waterpik, Ft Collins, CO, USA) using Type I rigid tray material with the interocclusal records (Take 1, Kerr, Romulus, MI, USA). Wax patterns were made using inlay wax (Harward, Harward, Germany) and then casting was done using Metal ceramic alloy (Remanium CSe, Dentaurum J.P. Winkelstroeter $K G$, Ispringen, Germany). During the cast metal try-in marginal fit and passivity were evaluated (Figure 8).

The appropriate shade was then selected using the VITA shade guide (Vita Zahnfabrik, Badsackingen, Germany) and porcelain firing was done.

The PFM restorations for the maxillary and mandibular anteriors, premolars, and maxillary first molars were cemented temporarily with Provicol for two weeks then permanently cemented with GIC Fugi II cement ( GC, Tokyo, Japan) (Figure 9).

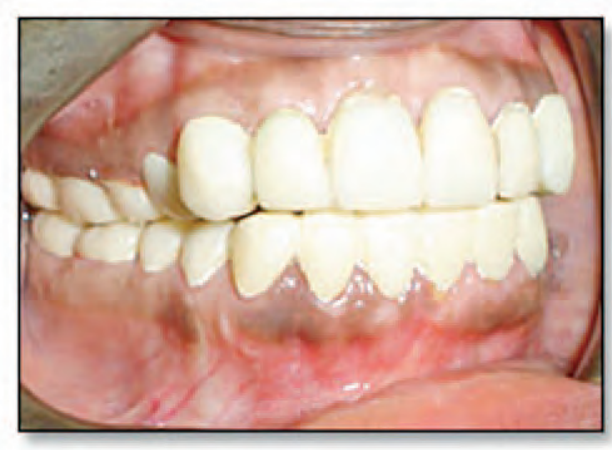

Figure 7. Photograph showing full mouth heat cure processed provisional restoration which was fabricated at the desired vertical dimension.

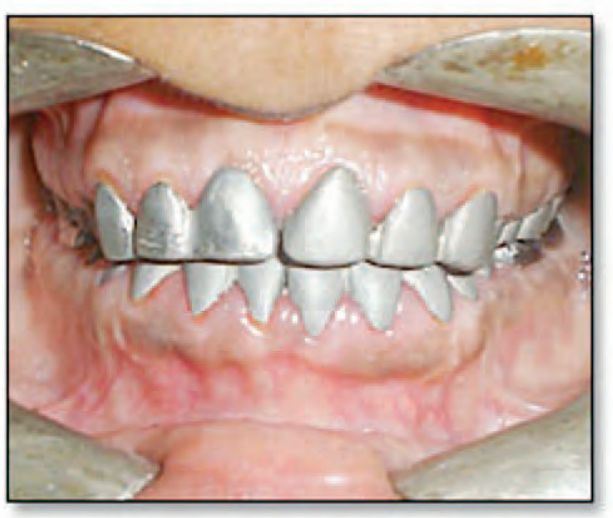

Figure 8. Photograph showing the cast metal try-in for evaluation of marginal fit and passivity.

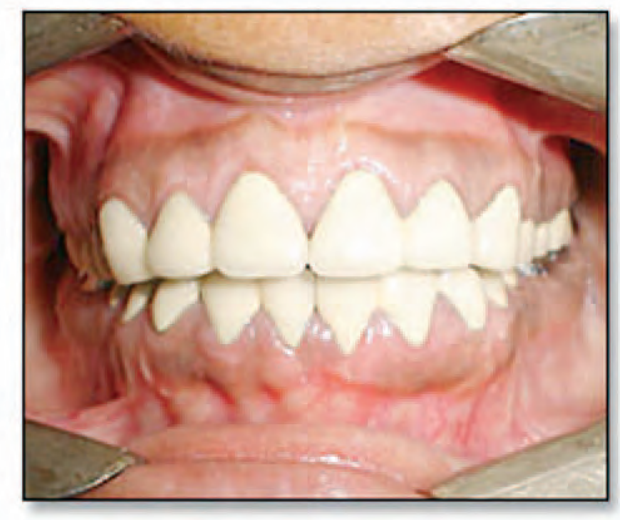

Figure 9. Photograph showing anterior view of the rehabilitated dentition in occlusion, one year after treatment. 


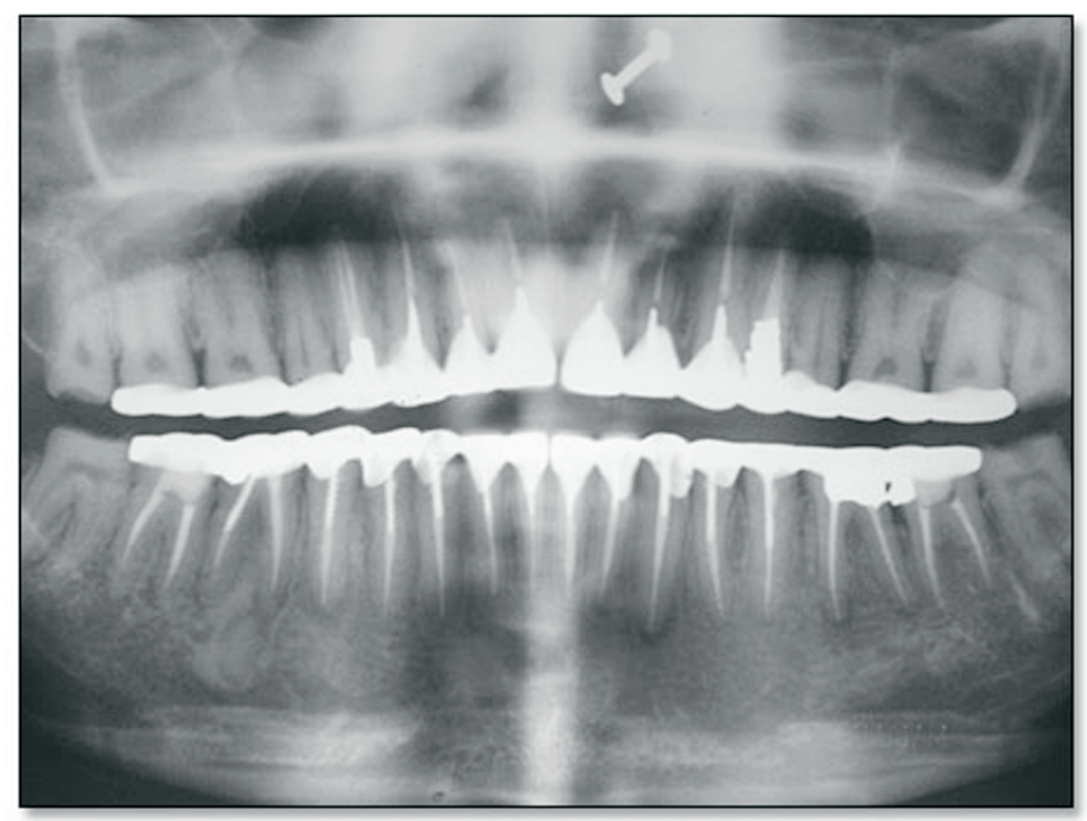

Figure 10. A post-operative panoramic radiograph of the patient's dentition one year after treatment.

Since there was no concern regarding esthetics, full cast metal restorations were fabricated for the remaining teeth. Oral hygiene instructions were given again.

The crowns were splinted together with wide embrasure spaces for maintenance to provide adequate retention and resistance form. The disadvantages of splinting the teeth include the need for frequent follow up visits and meticulous oral hygiene measures.

The patient was satisfied with the treatment outcome and is following a strict three month recall program. The patient's dental sensitivity disappeared and normal eating habits were established. Figure 10 is a panoramic radiograph taken at the one year recall visit which showed no evidence of any disorder associated with the restored teeth or their supporting structures. The psychological change which was seen in the patient was appreciable.

\section{Discussion}

Based on the clinical presentation and strong family history a diagnosis of $\mathrm{Al}$ (hypocalcified, autosomal recessive type) was made. An accurate diagnosis is important clinically for several reasons. First, one has to exclude the presence of systemic diseases that may show generalized enamel hypoplasia. Secondly, an accurate diagnosis enables genetic counseling which is often sought by affected families. Finally, an accurate diagnosis helps in recognition of the condition so preventive measures can be provided early.

According to Seow ${ }^{2}$ the primary clinical problems of $\mathrm{Al}$ are esthetics, dental sensitivity, and loss of vertical dimension. These patients are highly susceptible to dental caries, gingival inflammation, as well as an anterior and posterior open bite.

Treating the patient with $\mathrm{Al}$ is important for functional and psychosocial reasons. Some patients need only oral hygiene instructions, while others need extensive dental treatment. Historically treatment of such patients had included extractions and fabrications of complete dentures, however, these options are psychologically displeasing to the patient.

The following are general treatment steps suggested for patients with $\mathrm{Al}$ :

\section{Preventive and Initial Phases:}

- Oral hygiene instructions and oral prophylaxis.

- Chlorhexidine mouth rinses.

- Topical fluoride application.

- Control of dentinal hypersensitivity using desensitizing agents. 
- Extraction of teeth which have a poor prognosis.

- The initial provisional stage of treatment should be performed as soon as Al is diagnosed when the patient is cooperative.

\section{Restorative Phase:}

- Establish a favorable occlusal vertical dimension using a provisional occlusal splint.

- Composite build up of the teeth with severe loss of tooth structure.

- Fabricate thin gold crowns for posterior teeth.

- Lengthen the crowns of the worn teeth.

- Fabricate metal-ceramic crowns, all ceramic crowns, or porcelain veneers if the enamel is suitable for bonding for teeth where esthetics is a concern.

\section{Maintenance Phase:}

- Monitor oral hygiene, periodontal, and pulpal status.
Because of the recent advances in the field of esthetics and prosthetic dentistry, it is possible to restore the function and esthetics to an acceptable level in severe Al cases.

\author{
Summary \\ Management of a patient with $\mathrm{Al}$ is a challenge \\ for the clinician. The treatment options vary \\ considerably depending on several factors such \\ as the age of the patient, socio-economic status, \\ periodontal condition, loss of tooth structure, \\ severity of the disorder, and, most importantly, \\ the patient's cooperation. The clinician has \\ to consider the long-term prognosis of the \\ treatment outcome. This clinical report describes \\ the fabrication of metal ceramic and all metal \\ crowns for the restoration of severely worn teeth \\ in a patient with $\mathrm{Al}$ which requires meticulous \\ maintenance of oral hygiene and patient \\ co-operation.
}

\section{References}

1. Robinson FG, Haubenreich JE. Oral rehabilitation of a young adult with hypoplastic amelogenesis imperfecta: a clinical report. J Prosthet Dent 2006 Jan;95(1):10-3.

2. Sari T, Usumez A. Restoring function and esthetics in a patient with amelogenesis imperfecta: a clinical report. J Prosthet Dent 2003 Dec; 90(6):522-5.

3. Lindunger A, Smedberg JI. A retrospective study of the prosthodontic management of patients with amelogenesis imperfecta. Int J Prosthodon, 2005 May-June; 18(3):189-94.

4. Bouvier D, Duprez JP, Pirel C, Vincent B. Amelogenesis imperfecta - a prosthetic rehabilitation: A clinical report J Prosthet Dent 1999 Aug; 82(2):130-1.

5. Witkop CJ Jr. Amelogenesis imperfecta, Dentinogenesis imperfecta and dentin dysplasia revisited: problems in classification. J Oral Pathol 1988: 17;547-53.

6. Kostoulas I, Kourtis S, Andritsakis D, Doukoudakis A. Functional and esthetic rehabilitation in amelogenesis imperfecta with all-ceramic restorations: a case report. Quintessence Int 2005 May; 36(5):329-38.

7. Yip HK, Smales RJ. Oral Rehabilitation of young adults with amelogenesis imperfecta. Int $J$ Prosthodont 2003 July-Aug 16(4):345-9.

8. Wright JT. The molecular etiologies and associated Phenotypes. Am J Med Genet A, 2006 Dec 1; 140(23):2547-55.

9. Stephanopoulos G, Garefalaki ME, Lyroudia K. Genes and related proteins involved in amelogenesis imperfecta. J Dent Res 2005 Dec; 84(12):1117-26.

10. Light El, Rakow B, Fraze RL. An esthetic transitional treatment for amelogenesis imperfecta: report of two cases. J Am Dent Assoc 1975 Jan; 90(1):166-70.

11. Rosenblum SH. Restorative \& Orthodontic treatment of an adolescent patient with amelogenesis imperfecta. Pediatr Dent 1999 Jul-Aug; 21(4):289-92.

12. Sengun A, Ozer F. Restoring function and esthetics in a patient with amelogenesis imperfecta: a case report. Quintessence Int 2002 Mar; 33(3):199-204.

13. Lamb DJ The treatment of amelogenesis imperfecta. J Prosthet Dent 1976 Sep; 36(3):286-91.

14. Bauvier D, Duprez JP, Bois D. Rehabilitation of young patients with amelogenesis imperfecta: a report of two cases. ASDC J Dent Child 1996 Nov-Dec; 63(6):443-7.

15. Storic DQ, Cheatham JL. Management of amelogenesis imperfecta by Periodontal \& Prosthetic Therapy. J Prosthet Dent 1970 Dec; 24(6):608-15. 
16. Mackie IC, Blinkhorn AS Amelogenesis imperfecta: early interception to prevent attrition. Dent update 1991 Mar; 18(2):79-80.

17. Coley-Smith A, Brown CJ. Case report - radical management of an adolescent with amelogenesis imperfecta. Dent update 1996 Dec; 23(10):434-5.

\section{About the Authors}

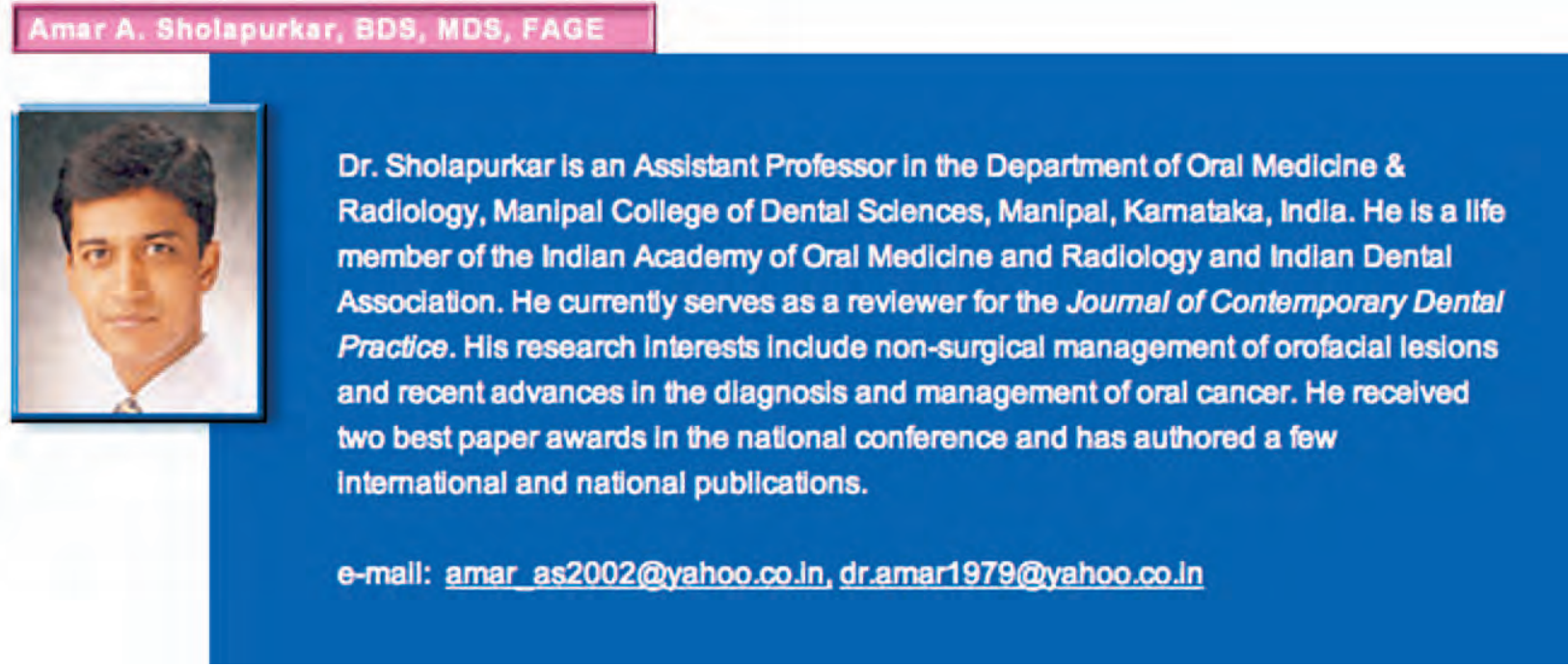

\section{Robin Mathal Joseph, BDs, MDS}

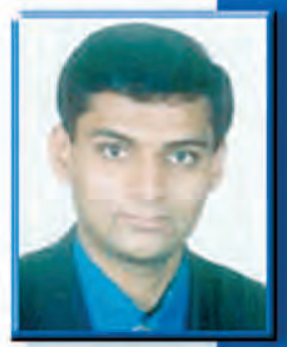

Dr. Joseph is a former postgraduate student in the Department of Prosthodontics of the Manipal College of Dental Sclences in Manipal, Kamataka, Indla. He recelved two best paper awards in the National conferences. His research Interests Include material sciences. He is a life member of the Indlan Prosthodontic Society and the Indian Dental Association.

e-mall: dr robin@hotmall.com

\section{Jothi M. Varghese, BDS, MDS}

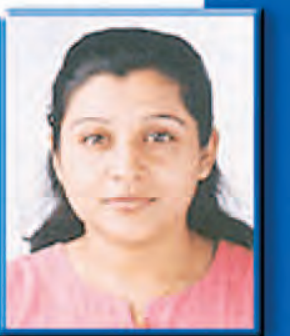

Dr. Varghese is a former postgraduate student in the Department of Periodontics of the Manipal College of Dental Sclences In Manipal, Kamataka, Indla.

e-mall: [othljaison@hotmall.com 


\section{Krishna Noolagiri, BDS, MDs}

Dr. Neelagiri is a former postgraduate student in the Department of Conservative Dentistry of the Manipal College of Dental Sclences In Manipal, Kamataka, Indla.

e-mail: endo@manipal.edu

\section{Shashi Rashmi R. Acharya, BDS, MDS}

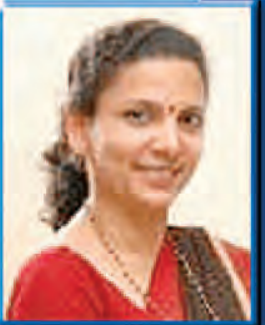

Dr. Acharya is a Professor and Head of the Department of Conservative Dentistry at the Manipal College of Dental Sclences in Manipal, Kamataka, Indla. She is a life member of the Federation of Operative Dentistry of Indla and the Indlan Endodontic Soclety. She has authored more than ten international and national publications.

e-mall: sracharya@manipal.edu

\section{Veana Hegdo, BD8, MDS

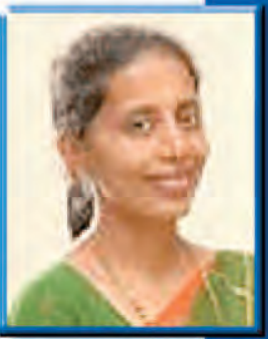 national publications. \\ e-mail: drveenahebbar@yahoo.com}

Dr. Hegde is a Professor and Head of the Department of Prosthodontics at the Manipal College of Dental Sclences in Manipal, Kamataka, Indla. Her research Interests Include fixed partial dentures. She is a life member of the Indian Prosthodontic Soclety and the Indian Dental Association. She has authored more than ten International and

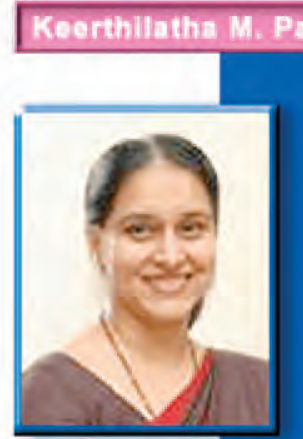

Dr. Pal is a Professor and Head of the Department of Oral Medicine and Radiology at the Manipal College of Dental Sclences In Manipal, Kamataka, Indla. She has authored more than $\mathbf{5 0}$ international and national publications. Her current research Interests include recent advances in the diagnosis of oral cancer. She is a life member of the Indian Academy of Oral Medicine and Radlology.

e-mall: omr@manipal.edu 


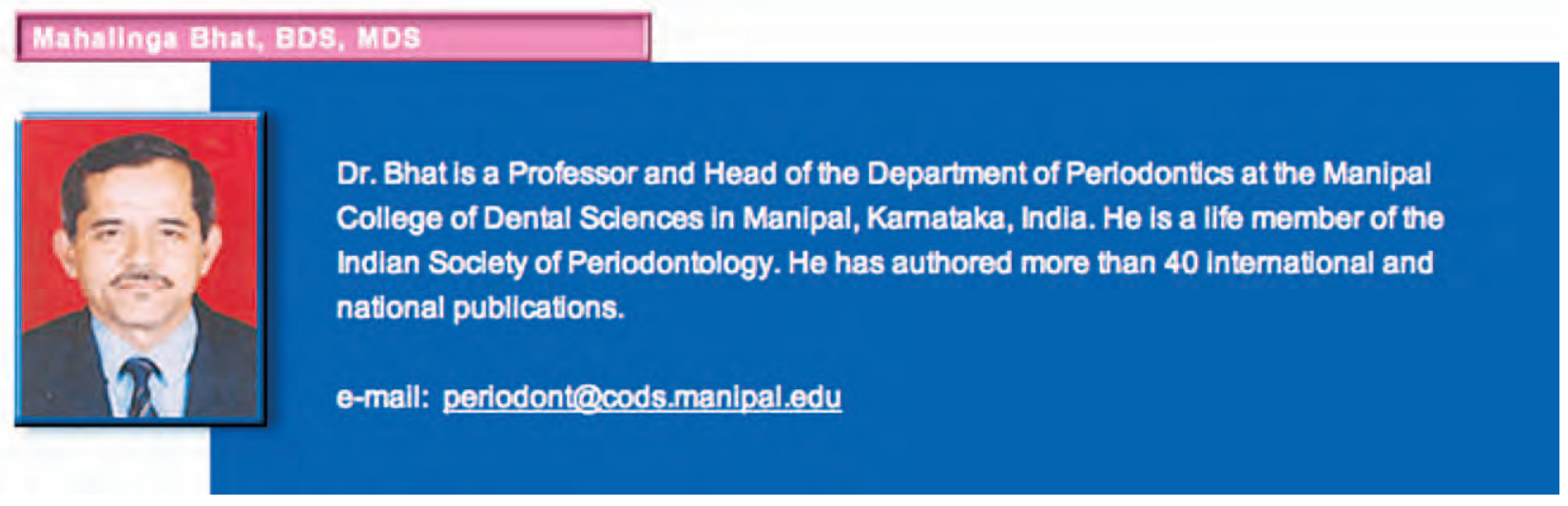

